arch and the left subclavian artery and distal arch replacement. We reconstructed the total thoracic aortic system by using an extra-anatomic bypass via the pericardial cavity without a cardiopulmonary bypass, and controlled the infection. We believe that this is a useful strategy for the treatment of distal aortic arch graft infections.

\section{References}

1. Darouiche RO. Treatment of infections associated with surgical implants. $N$ Engl J Med. 2004;350:1422-9.
2. Perera GB, Fujitani RM, Kubaska SM. Aortic graft infection: update on management and treatment options. Vasc Endovascular Surg. 2006;40:1-10.

3. Hart JP, Eginton MT, Brown KR, Seabrook GR, Lewis BD, Edmiston CE Jr, et al. Operative strategies in aortic graft infections: is complete graft excision always necessary? Ann Vasc Surg. 2005;19:154-60.

4. Sai N, Maeda M, Miyahara K, Sakurai H, Nakayama M, Takemura H. A case of primary squamous cell lung cancer invading the wall of the distal aortic arch and the left subclavian artery: successful surgical management using ECC selective cerebral perfusion. Nippon Geka Gakkai Zasshi. 1998;99:264-7 [in Japanese]

5. Kazuyoshi T, Fumio $\mathrm{Y}$, Kohei K, Izumi N, Hiroshi S, Toshio A, Yasunaru K. Cardiopulmonary bypass and cellular immunity: changes in lymphocyte subsets and natural killer cell activity. Ann Thorac Surg. 1993;55: 625-30.

\title{
Single-stage repair of aortopulmonary window with interrupted aortic arch by transection of the aorta and direct reconstruction
}

\author{
Masahiro Yoshida, MD, ${ }^{\mathrm{a}}$ Masahiro Yamaguchi, $\mathrm{MD}, \mathrm{PhD},{ }^{\mathrm{b}}$ Yoshihiro Oshima, MD, PhD, ${ }^{\mathrm{a}}$ \\ Shigeteru Oka, MD, PhD, ${ }^{\mathrm{a}}$ Tomonori Higuma, MD, ${ }^{\mathrm{a}}$ and Yutaka Okita, MD, PhD, ${ }^{\mathrm{c}}$ Kobe and Akashi, Japan
}

Aortopulmonary window (APW) associated with interrupted aortic arch (IAA) is a rare congenital heart defect that requires early surgical treatment to avoid the progression of pulmonary hypertension. ${ }^{1}$ Single-stage repair is currently the preferred approach because of its potential to provide normal systemic and pulmonary circulations. ${ }^{2,3}$ We report a new technique of single-stage repair for this complex entity by transection of the aorta and direct reconstruction of both aorta and pulmonary artery.

\section{TECHNIQUE}

The operation is performed through a median sternotomy. Cardiopulmonary bypass is established by brachiocephalic arterial and bicaval cannulations. The aortic arch and the descending aorta are dissected completely. After clamping of the proximal arch, the left carotid artery, the left subclavian artery, and the descending aorta, the lesser curva-

\footnotetext{
From the Department of Cardiovascular Surgery, ${ }^{a}$ Kobe Children's Hospital, Kobe, Japan; the Department of Cardiovascular Surgery, ${ }^{\mathrm{b}}$ Akashi Medical Center, Akashi, Japan; and the Division of Cardiovascular, Thoracic, and Pediatric Surgery, ${ }^{\mathrm{c}}$ Kobe University Hospital, Kobe, Japan.

Received for publication April 10, 2008; accepted for publication July 6, 2008; available ahead of print Sept 25, 2008.

Address for reprints: Masahiro Yoshida, MD, Department of Cardiothoracic Surgery, Kobe Children's Hospital, 1-1-1 Takakuradai Suma-ku, Kobe, 654-0081, Japan (E-mail: masahiro.yoshida@chp.edu).

J Thorac Cardiovasc Surg 2009;138:781-3

$0022-5223 / \$ 36.00$

Copyright $(C) 2009$ by The American Association for Thoracic Surgery

doi:10.1016/j.jtcvs.2008.07.031
}

ture of the aortic arch is opened. Ductal tissue is removed completely after transection of the descending aorta. The aortic arch reconstruction is completed with side-to-end anastomosis between the arch and the descending aorta (Figure 1, A). After crossclamping of the aorta, the blood cardioplegia is infused, and the ascending aorta is divided from the connecting pulmonary artery along the specially designed division line, as shown in Figure $1, B$. The main and right pulmonary arteries are repaired by direct suture, and the ascending aorta is also reconstructed directly (Figure 1,C).

\section{CLINICAL SUMMARIES}

Since Yamaguchi, the former director of cardiovascular surgery in Kobe Children's Hospital, performed the first case in 2002, a total of 3 consecutive patients with a diagnosis of APW with IAA have undergone single-stage repair with this technique at the ages of 5 months, 2 months, and 5 days. According to the Cerolia and Patton classification for $\mathrm{IAA}^{4}$ and the Richardson classification for $\mathrm{APW},{ }^{5}$ all cases were type A of IAA and types I and II of APW, which means that the defect was very large from just above the sinus of Valsalva to the right pulmonary artery. In all cases, single-stage repair was performed successfully by direct reconstruction of the aorta and pulmonary artery with our technique. In the most recent case, in addition to brachiocephalic arterial and bicaval cannulations, blood circulation to the lower half body was maintained by descending aortic cannulation. The cardiopulmonary bypass and crossclamping times were $165 \pm 26$ and $58 \pm 21$ minutes, respectively. 

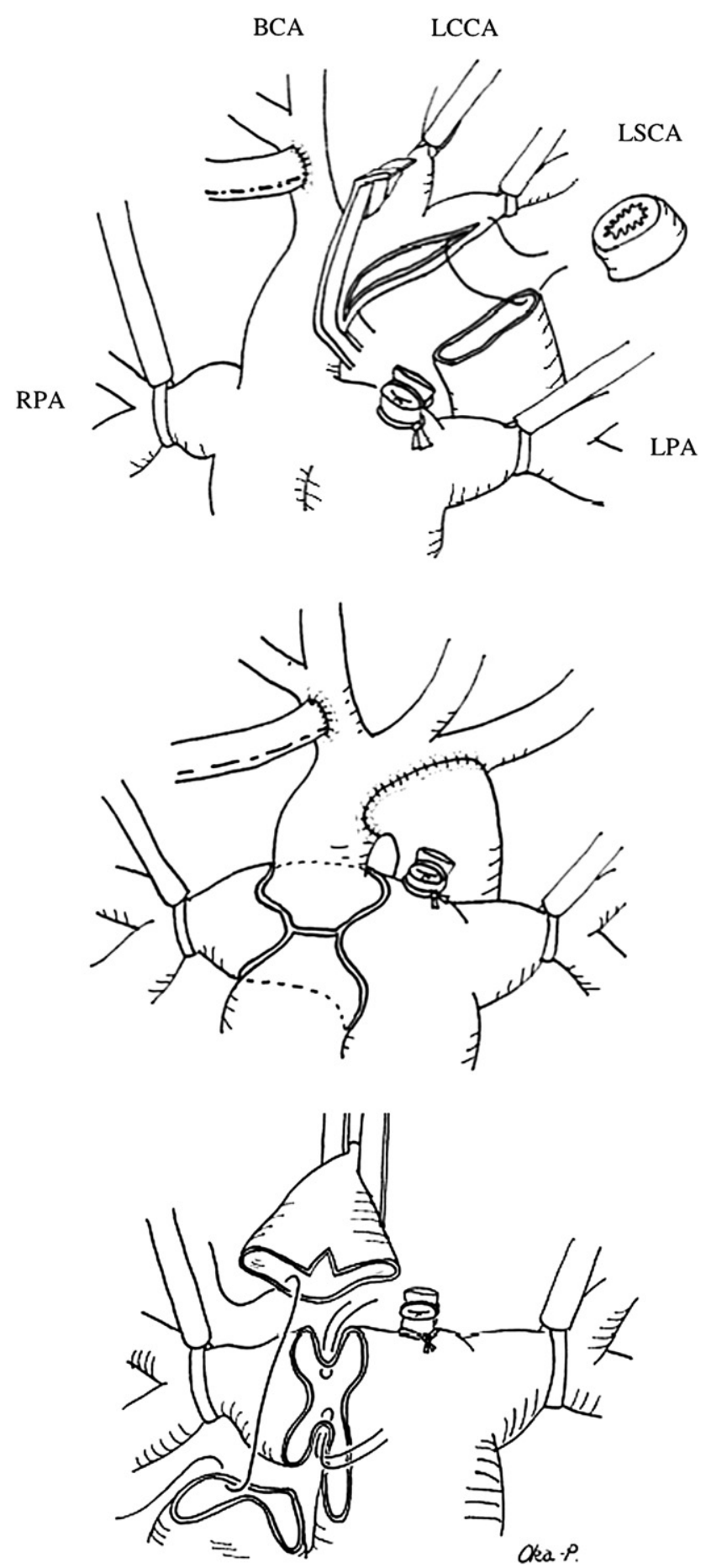

FIGURE 1. Schema of operation. Designed division line of aortopulmonary window (center): anterior transecting incision on aorta; laterally divided along border between aorta and pulmonary artery; posteriorly division line into pulmonary arterial wall by 2 to $3 \mathrm{~mm}$ in width apart from border, reserving sufficient tissue for reconstruction of posterior aortic wall. $B C A$, Brachiocephalic artery; $L C C A$, left common carotid artery; $L S C A$, left subclavian artery; $R P A$, right pulmonary artery; $L P A$, left pulmonary artery.
In all cases, the postoperative course was uneventful. All patients are doing well, without detectable pressure gradients across the reconstructed aorta and pulmonary artery on echocardiography at $3.9 \pm 2.9$ years after the operations. In the latest case, 3-dimensional computed tomography showed the great arteries to be almost normal, without any stenosis (Figure 2).

\section{DISCUSSION}

APW is a relatively rare congenital heart disease that requires early repair to avoid irreversible pulmonary hypertension. IAA is the lesion most frequently encountered in association with APW and is an independent risk factor for death. ${ }^{2}$ There have been several reports of single-stage repair with materials interposed to close the defect between the aorta and the pulmonary artery. ${ }^{1,2}$

We developed a new technique to repair APW with IAA by transection of the aorta along the specially designed division line followed by direct reconstruction without introduction of foreign materials. Pulmonary stenosis and recurrent coarctation of the aortic arch are not rare after repair of this complex disease with patch techniques. ${ }^{1,2}$ Our method carries the advantage of growth potential, potentially avoiding these recurrent problems.

Single-stage repair with a pulmonary arterial flap, as reported by Chiu and colleagues, ${ }^{3}$ can also be performed without the use of any foreign materials and also has growth potential. Our method is more anatomically and physiologically accurate, however, to the point of providing aortic and pulmonary arterial walls that could avoid distortion and residual shunting.

Our method could cause the overstretching of the right pulmonary artery from the direct anastomosis to the pulmonary trunk. We believe that this could be avoided easily by extended exposure of the right pulmonary artery and the pulmonary trunk, because both of these structures are already enlarged and elongated and thus easy to bring together in a patient with this complex disease.

Echocardiographic evaluation has revealed no recurrent problems of aortic or pulmonary stenosis in any of our cases, with the longest follow-up currently 5 years after the operation. Longer follow-up, however, may be necessary to confirm sustained growth.

\section{CONCLUSIONS}

We report here the new technique of repairing APW with IAA by transection of the aorta and direct reconstruction without foreign materials. The results of 3 cases so far indicate that the growth potential of both great arteries is well preserved with this technique. 

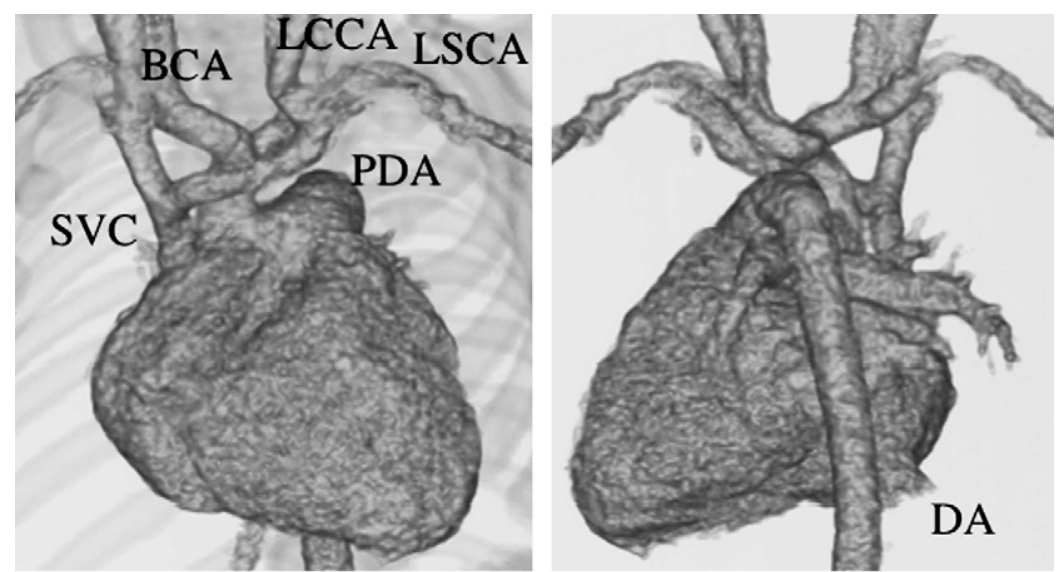

A

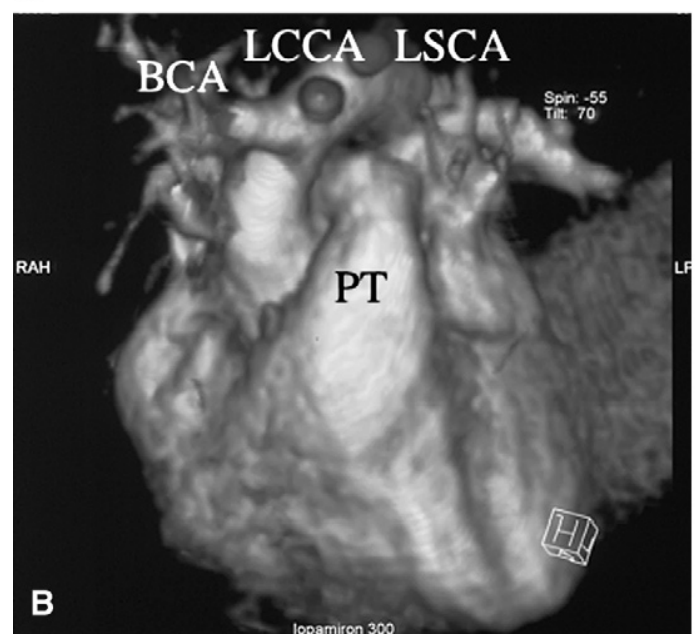

FIGURE 2. Preoperative (A) and postoperative (B) 3-dimensional computed tomography of latest case. $B C A$, Brachiocephalic artery; $L C C A$, left common carotid artery; $L S C A$, left subclavian artery; $P D A$, patent ductus arteriosus; $S V C$, superior vena cava; $D A$, descending aorta; $P T$, pulmonary trunk.

\section{References}

1. Konstantinov IE, Karamlou T, Williams WG, Quaegebeur JM, del Nido PJ, Spray TL, et al. Surgical management of aortopulmonary window associated with interrupted aortic arch: a Congenital Heart Surgeons Society study. J Thorac Cardiovasc Surg. 2006;131:1136-41.

2. Bagtharia RI, Trivedi KR, Burkhart HM, Williams WG, Freedom RM, Van Arsdell GS, et al. Outcomes for patients with an aortopulmonary window, and the impact of associated cardiovascular lesions. Cardiol Young. 2004;14:473-80.
3. Chiu IS, Wu SJ, Lee ML. One-stage repair of interrupted aortic arch and aortopulmonary window with an autologous arterial flap. J Card Surg. 1999; 14:306-9.

4. Cerolia GC, Patton RB. Congenital absence of the aortic arch. Am Heart J. 1959; 58:407-13.

5. Richardson JV, Doty DB, Rossi NP, Ehrenhaft JL. The spectrum of anomalies of aortopulmonary septation. J Thorac Cardiovasc Surg. 1979;78: 21-7. 